\title{
Re-envisioning paediatric nurse training in a re-engineered health care system
}

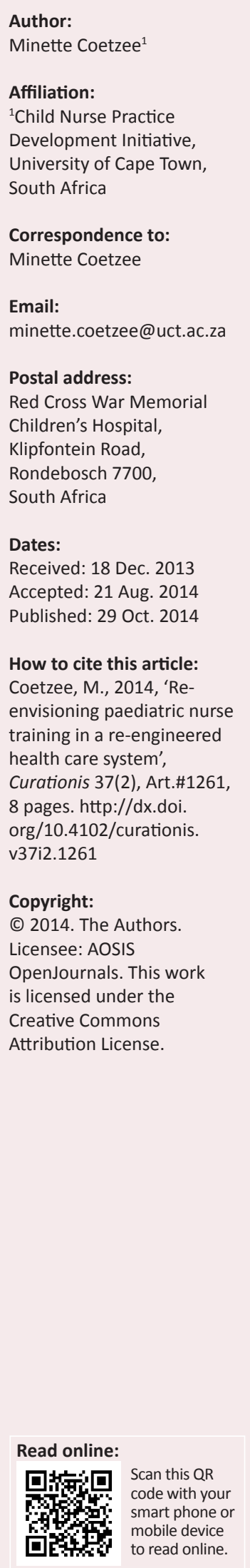

Background: South African's infant and child mortality rates remain high and at the current rate of decline will not meet the Millennium Development Goals of a two thirds decrease by 2015. At the latest available count, there were fewer than 1500 qualified paediatric nurses on the National South African Nursing Council register, with only about 100 nurses graduating with this qualification from South African nursing schools annually. It is not clear, however, if current paediatric nurse training programmes adequately equip nurses to make a real impact on reducing the under-5 mortality rate. In their 2011 interim report, the Ministerial Committee on Morbidity and Mortality in Children under 5 years recommended strengthening paediatric nurses' training as a strategy to reduce the under-5 mortality rate.

Method: In response to the Committee on Morbidity and Mortality in Children recommendation, a colloquium was convened as a national forum for schools of nursing, departments of health, health care facilities, clinicians and regulatory bodies to advance children's nursing in South Africa.

Objectives: The goals of the colloquium were to thoroughly investigate the situation in South Africa's paediatric nurse training, plot ways to strengthen and expand postgraduate paediatric programmes to meet priority child health needs, and to build relationships between the various schools and stakeholders.

Results: Outcomes included the clarification and strengthening of a 'stakeholder grid' in nurse training, recognition of the need for more active teaching and learning strategies in curricula linked to national child health priorities, as well as the need to develop and support clinical nursing practice in facilities.

\section{Introduction \\ Problem statement}

Close to one million babies were born in South Africa in 2011 (Statistics South Africa 2013). In the same year, only 112 children's nurses graduated from South African nursing schools. At our current under-5 mortality rates, more than 99000 of these children will die before their 5th birthday. The numbers of registered paediatric nurses are therefore too few to make a significant impact on almost 100000 lives lost each year. Questions also remain as to whether current paediatric nurse training programmes in South Africa leave nurses adequately equipped to impact our under-5 mortality rate (U5MR).

When South African Minister of Health, Aaron Motsoaledi describes his vision of a long and healthy life for all South Africans, his qualifier is always: 'with a particular focus on improving maternal and child health' (South Africa, DoH 2011b:8). The current (2013) South African U5MR of 47 (Countdown to 2015, 2013) is still very far from reaching its 2015 Millennium Development Goal (MDG) of 20 per 1000 live births. A re-engineered Primary Health Care service, funded by a National Health Insurance scheme, is an exciting new strategy at National Department of Health $(\mathrm{DoH})$ level. Whilst it provides possibilities for improved child health and provision of health services, it also requires a renewed commitment to train and support paediatric nurses to ensure the delivery of best practice in local settings.

The causes of under-5 mortality are mostly preventable, but accelerating the downward trend towards the MDG will require a complex and multipronged approach in a re-engineered Heath Service. District Clinical Specialist Teams (DCSTs) have been appointed and established in a number of the 52 districts in South Africa. Community-based and School Health Services are being redesigned, and new health facilities for children are being planned and built (South Africa, DoH 2011c). In 2011, the Committee on Morbidity and Mortality in Children under 5 years (CoMMiC) published a number of strategies to address the complex issues affecting the 
U5MR; one of these was to strengthen training in paediatric nursing (South Africa, DoH 2011a).

Discussions held in early 2012 amongst heads of Schools of Nursing who offer postgraduate paediatric nursing, led the Child Nurse Practice Development Initiative to convene a colloquium in October 2012.

\section{Key Focus}

The purpose of the colloquium was to consider the national need for paediatric trained registered nurses and to strengthen this training. Whilst educators are traditionally responsible for curriculum design, preparation and implementation, the politicians, clinicians and nurse managers are responsible for ensuring improved outcomes and best practices in child and family care in healthcare settings, which range from households and clinics to district and regional health care services and hospitals. Therefore, participants from diverse settings were invited to contribute to the colloquium discussions.

\section{Background}

The United Nations Children's Fund (UNICEF) (2011) states that:

[C]hild mortality is a key indicator not only of child health and nutrition but also of the implementation of child survival interventions and, more broadly, of social and economic development. (p. 2)

It is also one of the key indicators used for monitoring the improvement of child health. Therefore, decreasing child mortality was an imperative for the South African government when they signed the global declaration on the eight United Nation's MDGs. MDG4 is specifically aimed at reducing child mortality by two thirds in every country by 2015 . Whilst the downward trend from 72.2 per 1000 in 2006 (Statistics South Africa 2012) to $47^{1}$ is encouraging, it is insufficient to meet the goal of 20 by 2015.

Strengthening paediatric nurse training is one strategy listed by CoMMiC to address South Africa's high U5MR. Internationally, the term 'children's nursing' is increasingly being used to describe this training. The training goes by a variety of names in South Africa. Some programmes are called 'paediatric nursing', others 'child health nursing', or, simply, 'child nursing'; whilst the curriculum focus may differ somewhat, all graduates are registrable with the South African Nursing Council (SANC) as trained paediatric nurses.

SANC-accredited programmes include diploma programmes that usually last one year and follow a fouryear undergraduate degree or diploma in general nursing. In South Africa, these programmes may be offered at post-basic or advanced diploma-level, which are at the current National

1.There is no consensus on a single figure as the official U5MR for the country (South Africa) and, as a result, there may be discrepancies between figures presented by different authors and sources in this Special Issue.
Qualifications (NQF) level 7, or as postgraduate diplomas at NQF level 8. Only four South African universities are currently accredited to train nurses in paediatric nursing, with only one university accredited to offer children's critical care nursing. A number of colleges still offer the post-basic diploma programme in paediatric nursing at NQF 7. These programmes will be realigned to be offered at NQF level 8, as established by the South African National Qualifications Sub-framework in 2013 (South Africa, Department of Education 2013).

In 2011, the DoH published the strategy document Human Resources for Health for South Africa as a call to action to realise improved health outcomes in a re-engineered Primary Health Care Service with improved capacity. The publication included the discouraging numbers of trained paediatric nurses registered with the South African Nursing Council (Figure 1 and Table 1). The steady annual decline in these numbers only contributes to the scarcity of qualified health personnel. Buchan and Aiken (2008) describe this scarcity as one of the biggest obstacles to achieving an effective health system.

\section{Trends}

Strengthening the training of paediatric nurses in South Africa is not simply a matter of increasing the numbers trained but also requires consideration of what nurses need to know and how they acquire the clinical and contextual knowledge and skills required to work efficiently with children, their families and communities. In a recent article, Swingler and colleagues (2012) questioned whether paediatricians' training was aligned with South African Health needs, a question nurse educators had not yet asked or sufficiently explored in relation to paediatric nursing.

Many childhood deaths are preventable and national audit tools like the Child Healthcare Problem Identification Programme (Child PIP) have revealed numerous avoidable and modifiable factors in all levels of the health care system and in homes and communities (South Africa, DoH 2011a). Nurses are at the core of delivering health services to children in clinics and hospitals. They are the primary providers of care, treatment and referral of sick children. Sadly, $50 \%$ of children who die do so before reaching the hospital, whilst the other 50\% die in hospital (South Africa, DoH 2012). Most of what paediatric nurses are trained to do is key to affecting the modifiable factors related to preventing under- 5 morbidity and mortality. This learning includes:

- recognition of severity of illness, early detection of growth, developmental delays and malnutrition

- skilled use of guidelines such as Integrated Management of Childhood Illness (IMCI)

- active facilitated referrals to higher levels of service which play a significant role in ensuring sick children get the care that they require

- in hospital, comprehensive history taking, clinical assessment and resuscitation, and actively enrolling parents and families in care to reduce readmissions. 


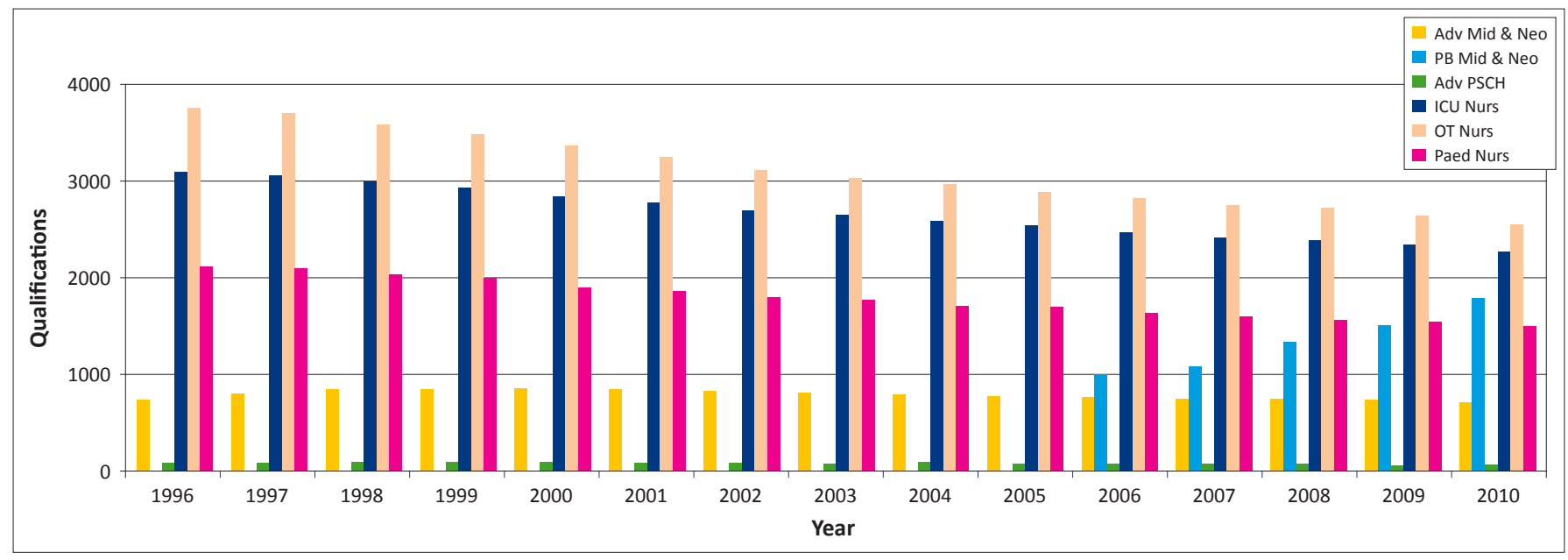

Source: South Africa, Department of Health, 2011c, Human Resources for Health South Africa HRH Strategy for the Health Sector: 2012/13-2016/17, Department of Health, Pretoria FIGURE 1: Nursing specialist qualifications, 1996-2010.

TABLE 1: Nursing specialist qualifications, 1996-2010.

\begin{tabular}{|c|c|c|c|c|c|c|c|c|c|c|c|c|c|c|c|}
\hline \multirow[t]{2}{*}{ Professional } & \multicolumn{15}{|c|}{ Year } \\
\hline & 1996 & 1997 & 1998 & 1999 & 2000 & 2001 & 2002 & 2003 & 2004 & 2005 & 2006 & 2007 & 2008 & 2009 & 2010 \\
\hline Adv. Mid. \& Neo. & 737 & 812 & 843 & 848 & 852 & 843 & 828 & 810 & 794 & 773 & 761 & 750 & 749 & 734 & 713 \\
\hline PB Mid. \& Neo & 0 & 0 & 0 & 0 & 0 & 0 & 0 & 0 & 0 & 0 & 990 & 1079 & 1347 & 1505 & 1793 \\
\hline Adv. Psch & 93 & 96 & 93 & 88 & 85 & 84 & 81 & 77 & 80 & 76 & 71 & 68 & 62 & 60 & 57 \\
\hline ICU Nurse & 3100 & 3050 & 2989 & 2929 & 2838 & 2779 & 2697 & 2649 & 2593 & 2537 & 2475 & 2408 & 2379 & 2339 & 2282 \\
\hline OT Nurse & 3755 & 3704 & 3582 & 3488 & 3364 & 3248 & 3109 & 3045 & 2962 & 2885 & 2815 & 2751 & 2711 & 2632 & 2546 \\
\hline Paed. Nurse & 2132 & 2093 & 2036 & 1992 & 1896 & 1856 & 1796 & 1769 & 1714 & 1681 & 1639 & 1601 & 1568 & 1541 & 1497 \\
\hline
\end{tabular}

Source: South Africa, Department of Health, 2011c, Human Resources for Health South Africa HRH Strategy for the Health Sector: 2012/13-2016/17, Department of Health, Pretoria

Re-envisioning the training of paediatric nurses in South Africa is thus an imperative for meeting the needs of South Africa's children in the context of a re-engineered health care system.

\section{Objectives}

A colloquium was planned by the ELMA Philanthropies and the Child Nurse Practice Development Initiative, with the goal of convening a national forum in response to the CoMMiC recommendation to strengthen South Africa's paediatric nurse training.

The objectives of the colloquium were to:

1. Begin to understand the current situation of paediatric nurse training in South Africa.

2. Consider ways to strengthen and expand postgraduate paediatric programmes to meet priority child health needs.

3. Build relationships between the various schools to develop a community of practice to advance child health nursing in South Africa.

4. Share a practice development approach, which links education, research and clinical practice, as a best practice methodology that should be incorporated in planned programmes.

The colloquium design was guided by the assumptions that schools had different theoretical positions, approaches and curricula and that programmes related to paediatrics and child health were at different stages of development.
It was planned that the need for further engagement and support would be explored, based on each institution's need, strategic direction and capacity to develop programmes.

\section{Contribution to the field}

This article provides necessary context for postgraduate education of paediatric nursing in South Africa. It clarifies the stakeholders involved, existing relationships in the training setting and the delivery of health services to children and families. The article further presents stakeholder recommendations to inform curriculum development and clinical learning strategies.

\section{Method}

A one-and-a-half day colloquium provided the setting for utilising a participative World Café approach (The World Café 2008) to actively engage participants from a variety of constituencies in key discussions to generate data describing the current situation of child nurse training in the country. This participative approach was used to prevent discussion contributions being limited to those of a number of 'perceived experts' only.

\section{Participants}

Thirty-eight stakeholders accepted invitations to participate, including heads of school and child nurse educators from the four SANC-accredited universities and colleges that currently offer programmes in the three children's nursing disciplines: child nursing, child critical care and neonatal critical care in 
South Africa; namely, the University of Pretoria (UP), the University of the Witwatersrand (UW), the University of the Free State (UFS) and the University of Cape Town (UCT).

Strategic representation further included participants from the SANC, ELMA Philanthropies, the Directorate of Nursing in the Western Cape, the National Department of Health, heads of nursing at major clinical services, as well as representatives from children's hospitals still in the planning stages, such as the Nelson Mandela Children's Hospital in Johannesburg and the Children's Hospital in Durban.

\section{Context}

The colloquium was convened in October 2012 in Cape Town. The location was deliberatively separate from any clinical setting; this allowed for full participation of those present and prevented interruptions from clinical or teaching responsibilities. The intentionally convivial atmosphere helped to facilitate conversations and relationships that may not otherwise have occurred in typical work settings.

\section{Data collection}

Intentional design of the colloquium to utilise World Café methodologies (The World Café 2008) and Graphic Harvesting techniques (Kelly 2005) facilitated the capturing of data in both transcribed and graphic forms. All participants were involved in gathering and reaching consensus on themes, which were initially discussed in small groups and then later with the group as a whole. As all participants contributed to each question discussion at different times, the assigned table host took responsibility for reaching consensus across five groups of participants and for reporting to the larger group. It is impossible to verify exactly what each participant said as the aim was to generate discussion and reach some consensus that was not considered an inaccuracy or limitation.

\section{Results}

Results are presented as five themes developed from five questions carefully crafted from discussion questions submitted by participants prior to the colloquium.

\section{Theme 1: Towards relevant and responsive child nurse training in South Africa}

The question which guided this conversation was: How can child nurse training remain relevant and responsive to the National Health Agenda?

This question elicited conversations around the relevance of current training in South Africa, especially in the light of shifting directives and clinical service delivery issues, such as quality and safety and child survival imperatives. International directives and guidelines have increasingly guided clinical service delivery. However, such guidelines have been traditionally excluded from curricula so that nurses may need additional training once they enter the practice. National and regional goals and strategies to decrease morbidity and mortality do not stay constant and the re-engineered health service, with its Primary Health Care approach as central, which recognises family and home as the pivotal unit of the community and health care, requires shifts in curricular focus.

Four main sub-themes emerged as educators reminded one another to align practice, teaching and student experience with current National DoH and Provincial policy:

1. Exploring ways of designing responsive and more flexible curricula.

2. The need to negotiate a recognised dual clinical plus teacher role for nurse educators to enable them to carry out clinical work. Currently, nurse educators are 'visitors' in clinical settings and clinical nurses rarely initiate interaction with the university.

3. Exploring the use of innovative teaching methods to engage students more actively in their learning, whilst enabling them to explore child health discussion forums and a variety of actual clinical settings, families and communities.

4. Ensuring that nursing research is fostered and intentionally linked to current child health issues and practice.

\section{Theme 2: Strengthening paediatric nursing training through support between stakeholders}

How can stakeholders, in the preparation of children's nurses, best support each other?

This question aimed to identify the stakeholders involved in strengthening paediatric nursing. The discussion explored how formal and informal relationships could be built and sustained between stakeholders, and considered the value of formal, bilateral and multilateral agreements. Clarifying the complexity of stakeholders was no easy task. In this regard, the graphic harvester (see Figure 2) played a key role by visually developing a stakeholder grid and by simplifying the numbers of stakeholders within this grid, and their relationships to each other.

Key stakeholders in child nurse training were identified as being the DoH, the Department of Education, SANC, higher education training institutions, such as universities and colleges, and health facilities such as clinics and hospitals. Additional stakeholders were identified as being professional bodies and unions, other health care providers and schools, students and the community. The elegant simplicity of this stakeholder grid will continue to assist participants in recognising relationships that need to be established or restored, to strengthen paediatric nurse training.

\section{Theme 3: The future role of paediatric nurses in the South African Health System}

Is there a role for postgraduate trained paediatric nurses in the South African Health System of 2020? 


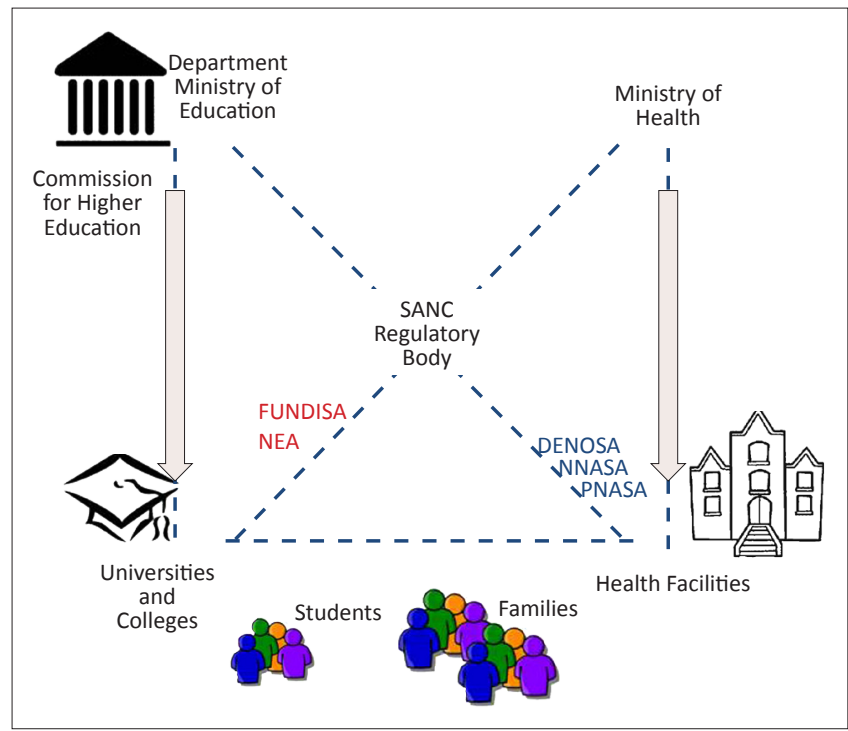

Source: Coetzee, M., 2014, 'Stakeholder Grid: Plotting the landscape of Nurse Education and Training in South Africa', adapted and developed from poster originated at the Nation Colloquium on Postgraduate Child Nursing in South Africa, Cape Town, 11-12 October 2012 SANC, South African Nursing Council.

FIGURE 2: Stakeholder Grid: Plotting the landscape of Nurse Education and Training in South Africa.

Colloquium participants unanimously agreed that postgraduate trained child nurses are required in South Africa's healthcare system. During discussions, participants developed a more accurate definition of postgraduate trained nurses. SANC currently has a number of registers for nurses who may be considered paediatric qualified nurses: paediatric critical care; critical care neonate; advanced midwifery and neonatal nursing; child nursing and primary health care nurses. At present there are still numerous different types of paediatric nursing training programmes, which provide eligibility for registration on any of the following levels: Bachelor of Nursing for Registered Nurses (degree for diploma with child nursing) (NQF7); post-basic diploma (NQF 7) or a postgraduate diploma (NQF8). The appropriate NQF level was still to be clarified by the South African Higher Education Qualifications Sub-framework (HEQSF) at the time of the colloquium, and was published in August 2013. This revised national standard now provides 'greater flexibility, in particular, in relation to the pathways for vocational and professional qualifications' (South Africa, Department of Education 2013:42). It establishes academic and qualification standards at different levels of specialisation training for registered nurses, namely for a postgraduate diploma at National Qualification Framework level 8 (NQF 8) and a masters degree at NQF level 9 (2013).

\section{The role of the postgraduate trained paediatric nurse}

There was further robust discussion on the role of these SANC registered and postgraduate trained paediatric nurses in the health care service. It became apparent that there was significant concern about services upstream not being well supported by paediatric nurses. Of particular concern was the current policy of training and locating community health workers as primary providers to assigned households in communities. Inadequate support would leave this valuable group of health care providers and their households more vulnerable. There was no dissent around the assumption that the health care of children and families needed strengthening from the ground up, but there was concern that the clinical role of qualified paediatric nurses in secondary and tertiary services in particular was being underestimated. As participants debated the exact nature of the paediatric nurses' role and the levels at which their expertise should be utilised in the healthcare system, there was consensus that they needed to have a clear primary health care approach but be clinically competent to recognise deterioration in a child's condition and to respond and act quickly and appropriately.

A significant role for paediatric nurses exists in directing nursing care to decrease the mortality and morbidity of children in hospital. There was a strong motivation and consensus that a key aim should be to have at least one paediatric trained nurse in every children's ward and more in tertiary facilities in South Africa.

The SANC participant issued an invitation for broad involvement in the development of the National Competencies set for registered child nurses. The opportunity to contribute to developing this role with the Human Resources Department at National Health level was also highlighted.

\section{Theme 4: Aligning evidence with practice}

How could content and actual practice in clinical facilities be better aligned in South African health settings?

The Institute for Healthcare Improvement (IHI) (2003) in the United States of America, maintains that there is a gap between what we know and what we do' (2003:1). This 'theory-practice gap' is well debated in the nursing literature (Landers 2000).

Participant discussions generated from the above question revolved around recent shifts in health care to a focus on quality and safety and the ways in which outcomes in child health care services are tracked and measured. Interestingly, these conversations not only focused on how clinical practice currently remains unaligned with current best practice evidence, but also on how taught curricula in nursing have not kept up with evidence-based practice norms, such as the use of the Perinatal Problem Identification Program (PPIP) and Child PIP in gathering morbidity and mortality statistics, and the use of algorithms and guidelines like the Integrated Management of Childhood Illness (IMCI).

The lively discussion generated around this question certainly indicated the imperative for increasing close relationships between training programmes and clinical facilities. Working relationships between educators, facility managers and clinicians would assist in aligning teaching and practice with evidence-based practice and policies.

This discussion called for a shift in attitudes to more intentional relationship-building and honouring of one another's roles and responsibilities. 


\section{Theme 5: Cultivating communities of discernment and support}

How do we offer our students the knowledge, skills and sensibilities required to cultivate communities of discernment and support in the current health care systems?

This question was based on the assumption that every serious effort at social change requires organised groups of people who can support each other when the demands of being a change agent threaten to overwhelm them. Such support can generate the collective power necessary to make a difference (Palmer 2011). Conversations around this question elevated the discussion to visions of students as part of a larger community. The numerous ideas proposed for actively engaging students in their learning and the practice of child health included: positive and active rolemodelling; building relationships between students across programmes; articulating and formalising credit for or recognition of continuous professional development; involving students in active, meaningful practice scenarios (to avoid dull and rote learning) and intentionally working towards growing postgraduates into 'whole' people - that is, being healthy themselves and participating actively in the community of professionals involved in improving child health outcomes in South Africa.

\section{Discussion}

\section{Outline of results}

The gravity of South Africa being off-track in meeting its targets for MDG4 highlighted the urgent need to consider aligning the training of paediatric nurses with priority child health needs in the country. Colloquium discussions confirmed an imperative for the growth of relationship between schools of nursing to strengthen and support national training. The value of intentional supportive relationships between heads of nursing schools and clinical facilities was also confirmed. It was further recognised that the introduction of a practice development approach to both settings could increasingly support the ways in which evidence-based care is embraced by schools and facilities.

\section{Practical implications}

Human resources: The scarcity of qualified paediatric nurses arose as a core concern at the colloquium. This scarcity and relative uncertainty of the particular role of this group of professional nurses in the health service may be the reason for participant's perception of the apparent underestimation of the contribution of professional nurses in current DoH policies and planning. Participant discussions resulted in a consensus regarding both the paediatric nurse's role and contribution at different levels of the health care service.

Training and collaboration: If the paediatric nurse's role in secondary and tertiary level facilities is primarily the nursing care of sick children that prevents further morbidity and mortality, then the question of what and how they are learning in formal institutions is the next relevant consideration. The training of health professionals remains the shared responsibility of universities and departments of health alike. Data gathered from this colloquium indicated little evidence of consistent collaboration between educators and clinician nurses within these two key stakeholder groups. Consensus was reached that curriculum redesign work is required in all post-registration training of paediatric nursing programmes and that active participation of clinical, facility-based contributors is very important if there is to be a commitment to relevant and appropriately trained paediatric nurses.

Curricula redesign in nature, content and methods: Discussions indicated that a redesign of curricula requires both the redesign of the nature and orientation of its content as well as of the teaching and learning methods utilised. Swingler and colleagues (2012) came to similar conclusions in their discussion of the orientation of paediatricians' curriculum. They propose community placement during training which, in addition to providing different learning opportunities, could augment skills in underserved areas (2012:738).

Differing approaches: It became further apparent that South African Schools of Nursing have historically designed paediatric nursing curricula in line with core theoretical frameworks of adult nursing. This approach is to be expected in schools with large under- and postgraduate nursing programmes, where paediatric nursing is usually one of a number of postgraduate programmes that share a general core, which incorporates professional practice, theories and research methods. Child nurse education requires the integration of several different core features. These include pathologies and physiological differences related to childhood development, different knowledge and skill sets related to the significant variability of responses and behaviour related to developmental stage and ability of children, and the specific challenges of shared decision making and participation related to attachment, family function and coping (Coetzee 2005). These core aspects are certainly more widely applicable to the education of paediatric nurses. Betz (2003:303) maintains that: 'Speciality of practice for adults and children requires two very different approaches to training, each with its own didactic content and clinical practica.'

NQF alignment: The newly published HEQSF (South Africa, Department of Education 2013) gives clear guidelines for professional nurse qualifications and requires schools of nursing to align all previous certificate and diploma courses to a Postgraduate Diploma at level NQF8. The clarification of the role of registered paediatric nurses will further inform how this alignment occurs. Since the colloquium in October 2012, the SANC has finalised a set of paediatric nurse competencies around which educators are now developing the postgraduate diploma qualification for submission to the South African Qualifications Authority. The SANC invited participation from clinician nurses as well as teachers of paediatric nurses in both these processes. This resulting 
set of competencies, as well as the qualification document developed, will guide re-curriculation of paediatric nursing programmes. Whilst this document is expected to address the standardisation of academic level requirements across other South African postgraduate diplomas at NQF level 8, the challenge of keeping content current and relevant to the South African situation will continue.

Suggestions for engaged teaching and learning: A further discussion topic related to curriculum redesign was data indicating the need for engaged teaching and learning strategies (Keller \& Suzuki 2010; Gordon et al. 2000; Barnard, Nash \& O'Brien 2005). Discussants spoke of exposing students to current child health discussion forums and a greater variety of actual clinical settings, families and communities. There were also discussions on how some schools of nursing managed to foster research and intentionally link findings to current child health issues and practice.

Interesting ideas for bridging the theory-practice gap included student participation in regular webinar series between training schools. Skills for accessing, understanding, presenting and discussing relevant evidence in journals, as well as skills required to assess, plan, evaluate and present particular children in case presentations were also discussed. One school has a well-equipped skills lab with high-fidelity simulation equipment, which could serve as a complex skills training environment for other schools. Encouraging the exploration of local best practice models and active student participation in developing resources for local clinical settings as part of their assignment load were other options discussed. Representatives from university schools engaged colleagues in conversations on the practical implementations of participating in, or leading, practice development projects in clinical settings.

Skilled clinical support in South Africa: In addition to the need for curricula that are more relevant to current clinical care and practice, the need for clinically skilled teachers was eagerly debated. The practical implications of dual clinical and educator roles were explored by department heads of nursing at universities and clinical facilities. It became clear that the current role of clinical educators was primarily the assessment of student skills but that there was little opportunity to work alongside students. So, whilst this role is well described as a clinical support role (Lambert \& Glaken 2006), in South Africa the reality is that it is more often a clinical assessment role. For many universityemployed educators, the opportunity to keep clinically active is a challenge. In this respect, the advantages of joint appointments, similar to those held by medical clinicians, in which the dual role of clinician and teacher can be filled without the perceived barriers of having to repeatedly negotiate access to clinical facilities, were discussed at length. The environment of the colloquium facilitated frank and productive discussions on this topic.

The advanced specialist paediatric nurse: Sister Jane Booth, a practicing, advanced specialist clinician nurse leading a home-ventilation programme in Cape Town, brought an interesting perspective to the question of the appropriate context for training specialist nurses for a health service with primary health care at its core. Her home ventilation model aims to decrease the length of stay in hospital of technologydependent children, through the active enrolment of both family and community in healthcare provision. In the last 20 years, this programme has seen to significant decrease in both the length of stay and hospital readmissions rates of these children (Bateman 2012).

Sister Booth manages a specific group of children with complex chronic illness and, whilst positioned in a tertiary care facility, she supports care in secondary and primary levels of health care, as well as across other sectors, including education, social services, housing and electricity. She provides a role model for the advanced specialist paediatric nurse. The advanced paediatric nurse planned for the DCSTs could be seen to similarly support clinical care at district level and, along with clinical governance and issues of quality and safety in health services in the district, would offer an advanced level of support in the healthcare of children.

This emerging role of advanced specialist paediatric nurses will require preparation and training at a level beyond the current postgraduate diploma. The HEQSF describes a professional masters degree or clinical masters degree for the advanced nurse specialist, that is, a new qualification, which poses exciting challenges and possibilities for interdisciplinary learning, advanced clinical practice and leadership in paediatric nurse training.

\section{Recommendations}

Causes of under-5 mortality are mostly preventable. Appropriately trained and deployed paediatric nurses can significantly contribute to the prevention of childhood morbidity and mortality. The consensus of the participating stakeholders was that each children's ward in each regional and district facility should have one registered paediatric nurse. In central hospitals, there should be at least one such nurse on each shift.

There are systems and infra-structure being put in place in the current South African healthcare system in the form of DCSTs, community health workers and school health teams. New health facilities are being built at secondary and tertiary level, whilst numerous existing buildings are being revamped. The scarcity of qualified paediatric nurses remains a core concern. Based on the latest available figures from SANC of the 1360 paediatric registered nurses included on the Register of Nurses and Midwives (SANC 2012), it is evident that South Africa needs to train and retain more paediatric nurses.

\section{Conclusion}

The current lack of collaboration between clinician nurses and nurse educators means that what is taught is not what 
usually happens in practice, and further, what happens in practice is based more on tradition than evidence. It should not be surprising then that nurse educators are concerned by what they see in practice settings, and that managers and clinicians are concerned that formally trained nurses need further courses in the programmatic approaches implemented to address child and infant mortality and morbidity. These approaches include IMCI, NimART (to initiate antiretrovirals), Helping Babies Breath, and Early Triage and Treatment (ETAT).

The forum established an excellent foundation for a shared commitment to support programme development in child nurse training. Through this collaboration, paediatric nursing educators will continue to challenge one another to redesign and maintain dynamic paediatric nursing curricula in line with current child health priorities in South Africa.

\section{Acknowledgements}

To the participants, nurse learners and leaders in academic institutions and clinical facilities and other clinicians who contributed and participated with keen enthusiasm. The ELMA Philanthropies for their sponsorship which enabled this diverse group of participants to engage in a face-to-face dialogue and debate to consider the landscape and direction of training and practice of paediatric nursing in an evolving Health Care System. Jean Morrissey for her assistance in compiling this article.

\section{Competing interests}

The author declares that she has no financial or personal relationship(s) that may have inappropriately influenced her in writing this article.

\section{References}

Barnard, A., Nash, R. \& O'Brien, M., 2005, 'Information literacy: Developing lifelong skills through nursing education', Journal of Nursing Education 44(11), 505-510, viewed 09 November 2013, from http://www.tandfonline.com/doi/ pdf/10.1080/1358165042000283084

Bateman, C., 2012, 'A dance of empowerment - lessons for the NHI?', South African Medical Journal 102(2), 62-66, viewed 13 August 2012, from http://www.samj. org.za/index.php/samj/article/view/5536/3811

Betz, C.L., 2003, 'Pediatric hospitals are not appropriate for adult admissions' (Editorial), Journal of Pediatric Nursing 18(5), 303-304, viewed 18 January 2005 from http://download.journals.elsevierhealth.com/pdfs/journals/0882-5963/ PIIS088259630300201X.pdf

Buchan, J. \& Aiken, L., 2008, 'Solving Nursing Shortages: A Common Priority', Journal of Clinical Nursing 17, 3262-3268, viewed 01 July 2013, from http://www.ncbi. nlm.nih.gov/pmc/articles/PMC2858425/pdf/nihms107153.pdf
Coetzee, M., 2005, 'Are children really different from adults in critical care settings?', South Africa Journal of Critical Care Nursing 21(2), 70-76, viewed 31 January 2005, from http://www.sajcc.org.za/index.php/SAJCC/article/view/49/55

Coetzee, M., 2014, 'Stakeholder Grid: Plotting the landscape of Nurse Education and Training in South Africa', adapted and developed from poster originated at the National Colloquium on Postgraduate Child Nursing in South Africa, Cape Town, 11-12 October 2012

Countdown to 2015 Maternal, Newborn \& Child Survival, 2013 'Accountability for Maternal, Newborn \& Child Survival: The 2013 Update', viewed 02 December 2013, from http://www.countdown2015mnch.org/documents/2013Report/ Countdown_2013-Update withprofiles.pdf

Gordon, J., Hazlett, C., Ten Cate, O., Mann, K., Kilminster, S., Prince, K. et al., 2000, 'Strategic planning in medical education: Enhancing the learning environments for students in clinical settings', Medical Education 34, 841-850, viewed 09 November 2013, from http://www.researchgate.net/publication/12310651 Strategic planning in medical education enhancing the Strategic_planning_o_medica_-_earning

Keller, J., \& Suzuki, K., 2010, 'Learner motivation and E-learning design: A multinationally validated process', Journal of Educational Media 29(3), 229239, viewed 09 November 2013, from http://www.tandfonline.com/doi/ pdf/10.1080/1358165042000283084

Kelly, S., 2005, 'The Benefits of Using Graphic Recording/Graphic Facilitation', viewed 02 April 2013, from http://www.theworldcafe.com

Lambert, V. \& Glacken, M., 2006, 'Clinical support roles: A review of the literature', Nurse Education in Practice 2004(4), 177-183, viewed 09 November 2013, from $\mathrm{http}: / /$ www.nurseeducationinpractice.com/article/S1471-5953(03)00039-8/pdf

Landers, M.G., 2000, 'The theory-practice gap in nursing: The role of the nurse teacher', Journal of Advanced Nursing 32(6), 1550-1556, viewed 04 August 2014 from http://onlinelibrary.wiley.com/doi/10.1046/j.1365-2648.2000.01605.x/full

Palmer, P., 2011, Healing the heart of democracy: The courage to create a politics worthy of the human spirit, Jossey Bass, San Francisco.

South Africa, Department of Education, 2013, The Higher Education Qualifications Sub-Framework (Notice 1040 of 2012; Government Gazette No. 36003 of 14 December 2012), in terms of the National Qualifications Act, 2008 (Act No. 67 of 2008) and as contemplated in the Higher Education Act, 1997 (Act No. 101 of 1997), Department of Education, Pretoria.

South Africa, Department of Health, 2011a, Committee on Morbidity and Mortality in Children, 1st Triennial Report of the Committee on Morbidity and Mortality in Children under 5 Years (COMMiC), Department of Health, Pretoria.

South Africa, Department of Health, 2011b, District Specialist Health Teams in South Africa-Ministerial Task Team Report, Department of Health, Pretoria.

South Africa, Department of Health, 2011c, Human Resources for Health South Africa HRH Strategy for the Health Sector: 2012/13-2016/17, Department of Health, Pretoria.

South Africa, Department of Health, 2012, Committee on Morbidity and Mortality in Children, Interim Report of the Committee on Morbidity and Mortality in Children under 5 Years, Department of Health, Pretoria.

South African Nursing Council (SANC), 2012, Additional Qualifications on the Register of Nurses and Midwives, viewed 30 June 2014, from http://www.sanc.co.za/ stats/stat2012/SANCStats2012AddQualsOnReg.pdf

Statistics South Africa, 2012, Levels and trends of morbidity and mortality among children aged under-five years in South Africa, 2006-2010, Report No. 03-09-10 (2006-2010), Statistics South Africa, Pretoria.

Statistics South Africa, 2013, 'Statistical Release P0305: Recorded Live births 2012', viewed 20 January 2014, from http://beta2.statssa.gov.za/publications/P0305/ P03052012.pdf

Swingler, G., Hendricks, M., Hall, M., Hall, S., Sanders, S., McKerrow, N. et al., 2012, 'Can a new paediatric sub-specialty improve child health in South Africa?', South African Medical Journal 102(9), 738-739, viewed 09 November 2013, from http://www.samj.org.za/index.php/samj/article/view/5714/4442

The World Café, 2008, 'Café to Go', viewed 02 April 2013, from www.theworldcafe. com

United Nations Children's Fund, 2011, Levels \& Trends in Child Mortality, UN Interagency Group for Child Mortality Estimation, UNICEF, New York.

United States of America, Institute for Healthcare Improvement, 2003, The Breakthrough Series: IHI's Collaborative Model for Achieving Breakthrough Improvement, Institute for Healthcare Improvement, Boston. 